\title{
Aproximaciones Semióticas a la Planificación desde la Comunicación
}

\author{
Carlos Federico GONZÁLEZ PÉREZ ${ }^{1}$ \\ Consejo Nacional de Investigaciones Científicas y Técnicas \\ Universidad Nacional de Jujuy (Argentina)
}

Al Prof. Juan Magariños de Morentín

(Pontevedra, 1935 - Jujuy, 2010)

\begin{abstract}
RESUMEN:
Este trabajo propone algunas consideraciones y desarrollos para poner en relación a la semiótica con la planificación prospectiva desde la comunicación.

Se aborda la semiótica considerada como una metodología disponible para las ciencias sociales desde el enfoque de Magariños de Morentín, y se aplica su lectura de los nueve signos al ámbito de la planificación. Se recurre a la perspectiva peirceana porque, además de ser una propuesta comunicacional, es un desarrollo de instancias de relación lógica que proponen un orden, una interrelación, un tiempo y hasta una estrategia, por lo que puede mantener una estrecha relación con la Planificación.
\end{abstract}

PALABRAS CLAVE: Comunicación; Planificación; Semiótica; Aplicaciones; Futuro

TITLE: Semiotics Approaches concerning Planning from Communication

ABSTRACT: This paper proposes some considerations and developments relating Semiotics to Planning from Communication.

Semiotics is an available methodology for social sciences. Magariños de Morentín's perspective is considered here, along with his interpretation of the nine signs, applied to the field of Planning.

Peirce's perspective it is used because, besides being a communication proposal, there are logical connection instances that propose an order, a relationship, a certain amount of time and even a strategy. This is why Semiotics can maintain a close relationship with Planning.

KEY WORDS: Communication; Planning; Semiotics; Applications; Future

\section{Introducción}

En este trabajo presentamos algunas posibles relaciones entre la semiótica y la planificación prospectiva desde la comunicación.

1 Licenciado en Comunicación Social, Universidad Nacional de Jujuy, Argentina. Becario de CONICET. Doctorando en Comunicación, Facultad de Periodismo y Comunicación Social, Universidad Nacional de la Plata, Argentina. Integra los proyectos de investigación Universidad de la Calle (Universidad Nacional de Jujuy) y el proyecto Ceremonias y Rituales Funerarios, su eficacia semiótica (Universidad Nacional de La Plata). Correo electrónico: carlosgonzalez@conicet.gov.ar 
Nos hemos interesado en una particular lectura de los nueve signos peirceanos, desarrollada por el profesor e investigador recientemente desaparecido Juan Magariños de Morentín, que permite una lectura operativa de esas relaciones lógicas.

Para la semiótica, un signo es algo que está en representación de otra cosa. En el caso de los signos de futuro ${ }^{2}$, concepto fundamental en planificación, esa otra cosa no es un existente concreto, sino que son signos que están en lugar de otra cosa que «aún no ha sido creada». Como eso a lo que el signo sustituye no ha sido creado, es aquí donde se puede dar lugar a la planificación, para que el desarrollo de esos signos de futuro se realice en un marco más o menos adecuado a diferentes situaciones que permitirán alcanzar ese futuro. Por lo tanto, desde la perspectiva de la semiótica de Charles S. Peirce, la naturaleza de estos signos podrá ser simbólica, puesto que es necesario construir ese futuro a partir de trabajo, consenso y convención; tendrá un aspecto, también importante, en sus características indiciales, existentes, materiales, y también incorporará aspectos icónicos, en cuanto a la posibilidad de que esas visiones o proyecciones de futuro contengan una forma a partir de la cual se desarrollarán.

\section{Algunos conceptos de la planificación prospectiva}

Para poder ingresar en el tema específico que se pretende tratar aquí, es necesario abordar algunos conceptos que recuperamos del enfoque de la planificación definida como prospectiva, y desde la comunicación ${ }^{3}$.

Aparece como primera cuestión la necesidad de explicar qué entendemos por planificación. Planificar implica mirar hacia un futuro, hacia un porvenir, hacia aspectos y lugares que pueden ser imaginados pero que aún no existen. Planificar es ordenar, prever, priorizar, evaluar recursos, caminos, operativizar, gestionar, decidir, etc. Uranga entiende la planificación como «un proceso mediante el cual se introduce racionalidad y sistematicidad a las acciones y a la utilización de los recursos con la finalidad de orientarlas hacia un objetivo deseable y probable» ${ }^{4}$. Es decir, que planificar no es sólo hablar de las actividades que se enumeraron, sino que implica pensar en un proceso que las pone en relación con criterios de racionalidad y persiguiendo objetivos, por lo que se puede decir que es mucho más que considerar la suma de esas partes por separado.

2 URANGA, W., (2007): «Mirar desde la comunicación», 14.

http://www.catedras.fsoc.uba.ar/uranga/uranga_mirar_desde_la_comunicacion.pd Web visitada el $15 / 10 / 2010$.

3 Hacemos referencia a los trabajos de, principalmente, Washington Uranga que se irán referenciando a lo largo del escrito.

4 UrangA, W. (2008): «Prospectiva estratégica desde la comunicación», $\mathrm{http}: / /$ catedrarollie.com.ar/taller5/wp-content/uploads/2008/06/prospectiva-estrategica-uranga.pdf. Web visitada el 28/04/2010, 7. 
Pero además, la perspectiva que presenta este autor se plantea desde la comunicación, ya que entiende que las prácticas sociales pueden ser leídas desde las enunciaciones de los sujetos sociales:

Las prácticas sociales son, desde lo comunicacional, «prácticas de enunciación» que se van construyendo a través de las narraciones, y mediante el desarrollo de habilidades y técnicas expresivas, un discurso que es entramado de la cultura y fundamento de la historia de la vida de una comunidad ${ }^{5}$.

Si se entiende que las prácticas se pueden manifestar, o materializar, a través de diferentes discursos, entonces éstas pueden ser abordadas desde el campo de la comunicación. Por supuesto que en la circulación y validación de esos discursos subyacen cuestiones vinculadas a su legitimación, al poder, a la interacción de los actores, y a la concepción de hegemonía. Es decir que la perspectiva comunicacional que se propone no refleja los modelos lineales de comunicación, sino procesos complejos. Tampoco se trata de una mirada ingenua de la misma, sino que parte de considerarla como un entramado complejo de significaciones que se contradicen, y mantienen relaciones dialógicas.

Para el mismo autor citado, la planificación en tanto proceso:

[...] puede partir tanto de una mirada que se apoya en la recopilación de lo hecho, de los antecedentes y de la enseñanza que de allí se deriva, como desde el futuro, construido como escenario soñado, como una imagen que le da direccionalidad a las acciones del presente. ${ }^{6}$

Es decir, que se está ante dos vertientes posibles de imaginar el futuro, pero que implican perspectivas diferentes: la proferencia y la prospectiva.

En opinión de Merello, la proferencia está conformada por «una serie de técnicas para adentrarse en el futuro que tienen en común el basarse en la experiencia. [...] se basan en el pasado para construir el futuro» ${ }^{7}$. El futuro se imagina desde un anclaje en el presente, pero recuperando y revisando sistemáticamente un pasado, a partir del que se extraen conclusiones de plausibilidad y viabilidad. El futuro desde la proferencia puede ser desarrollado desde tres diferentes técnicas: una tiene por eje la evaluación de las tendencias que pueden extrapolarse a un futuro que repite el presente (el autor habla de Futurible -en tanto futuro posible- o mundo tipo sin sorpresas); otra implica considerar un análisis de las combinaciones de variaciones canónicas que desembocarían en futuribles; y la tercera implica el desarrollo de escenarios que consisten en la construcción de los futuribles como punto final de la relación de diferentes hitos o eventos que se relacionan en una narración, que se define como guión.

URANGA, W., «Mirar desde...», 1.

UrANGa, W., «Prospectiva... », 7.

Merello, A. (1973): Prospectiva. Teoría y práctica, Buenos Aires, Editorial Guadalupe, 12. 
La otra vertiente que permite pensar en el futuro, y también tratada por Merello, es la prospectiva, considerada como «una sistemática mental que, en su tramo más importante, viene desde el futuro hacia el presente» ${ }^{8}$. Es decir, que la lógica operativa de esta técnica es inversa a la anterior, ya que se parte de un futuro, que es punto de partida para la elaboración de diferentes actividades que se encadenan desde el futuro al presente, pero que se ejecutarán desde el presente hacia el futuro una vez consolidadas.

La prospectiva es asumida por Washington Uranga en el sentido que se desprende de su etimología en latín: mirar lejos (prospicere). Esa visión es compartida por los actores sociales responsables de lo que construyen como futuro, «porque visión de futuro y construcción de futuros son herramientas básicas que permiten reducir las dependencias ganando en autonomías» ${ }^{9}$.

Desde la prospectiva se considera un futuro abierto, cambiante, que puede configurarse de diferentes maneras. Por ello aquí se habla de la configuración de futurables: futuros probables.

Para Merello, la prospectiva debe desarrollarse en tres etapas: la imaginación (polo de pensamiento) de un futuro probable o actitud prospectiva; una instancia de confrontación de ese futuro con la situación presente (permitiría diagnosticar la actualidad) o reflexión prospectiva; y una última instancia que permite ensamblar operaciones y acciones que surgen de la situación de diagnóstico para lograr el futurable.

Finalmente, dicho autor propone considerar dos cuestiones para pensar la realización de la acción: la factibilidad, que tiene que ver con la condición de posibilidad de concreción de las acciones (correcto desenvolvimiento de los componentes, eficacia técnica y financiera); y la aceptabilidad, como aquella perspectiva que un proyecto tiene de ser bien recibido y aprobado ${ }^{10}$. Esta dualidad, que puede ser vista como un doble peligro, queda solucionada y saldada en la propuesta de Prospectiva estratégica desde la comunicación de Uranga ${ }^{11}$, quien concibe cualquier actividad desde la participación, de modo que el proyecto es generado desde el involucramiento de diferentes actores (muchos serán beneficiarios de proyectos), por lo que el factor adhesión o aceptabilidad será mayor que el de otra planificación sin el involucramiento previo de actores.

La prospectiva implica pensar en el futuro: constituye sus genes, es su razón de ser. No debe ser vista como profecía o como previsión, sino que se trata de un futuro, como ya expresamos, abierto, al que cierta realidad se debe ir acercando, aproximando. Éste debe construirse; es, aún, una posibilidad.

El desarrollo de escenarios se vuelve una herramienta fundamental en planificación, ya que tiene por objetivo la identificación de lo que se considere prioritario

\footnotetext{
Ibidem, 18.

URAngA, W., «Prospectiva... », 3-4.

MERELlo (1973), op. cit.

Uranga, W., «Prospectiva... »
} 
en el estudio, realizando una descripción detallada de las variables del sistema que se aborda para explicar sus variables; «determinar, especialmente a partir de las variables claves, los actores fundamentales, sus estrategias, los medios de que disponen para realizar sus proyectos» ${ }^{12}$; describir la evolución del sistema, incluyendo las hipótesis comportamentales de los actores y las variables clave.

Maqueda Lafuente clasifica los escenarios en: Tendenciales: los que corresponden con la extrapolación de tendencias (sean probables o no); Referenciales: los más probables (sean tendenciales o no); y los Contrastados: son los escenarios que se imaginan en una situación contrastada respecto al presente (formulándose preguntas regresivas sobre el camino para llegar a ese escenario). Por su parte, Daniel Prieto propone otra clasificación para los escenarios: los escenarios catastróficos, que consisten en «la proyección de la situación actual, previendo cómo se irá agravando de no tomarse medidas ${ }^{13}$, por lo que sugiere que estos escenarios son los que permiten profundizar el diagnóstico; los escenarios ideales, en tanto reflejan «cómo nos gustaría que fuera la comunidad»; y los escenarios posibles, los que resultan de la «confrontación del ideal con las condiciones actuales, con el producto del diagnóstico».

El mismo Maqueda Lafuente establece determinadas fases para el diseño de un plan estratégico, en el que se desarrollarán los escenarios. La primera de esas fases implica la construcción de la base con una imagen del estado actual, de la organización o grupo social del que se trate y su contexto, la que debe incluir un detalle de aspectos cuantitativos y cualitativos, debe hacer alusión a su realidad global (económica, tecnológica, sociológica, etc.) y, como debe poner en relación las tendencias con los hechos portadores de futuro, debe ser también dinámica. Esta imagen también debe incluir una evolución del sistema que se estudia, con una profunda descripción del mismo que tienda a delimitarlo (a través de métodos como las entrevistas a especialistas, listas de verificación, etc.)

En otra etapa se deben generar hipótesis a partir de la relación de la evolución del sistema y las estrategias de los actores: «A cada juego de hipótesis corresponde un escenario que podemos construir y cuya realización es más o menos probable» ${ }^{14}$. Fases posteriores, como la cuantificación de escenarios, la definición de estrategias, y la elaboración de un balance y perspectivas completan el proceso. Desde el punto de vista empresarial, el desarrollo de escenarios es una herramienta que permite la gestión de los cambios, y es un deber y obligación de comunicación interna, constituyendo una herramienta de comunicación entre los dirigentes y los dirigidos por su transparencia interna.

Al hablar de estrategia se está involucrando a la acción, y a través de ésta a diferentes actores con diversas responsabilidades a lo largo del proceso de planifi-

12 Maqueda Lafuente (1996), op. cit., 93.

13 Prieto, D. (1990): Diagnóstico de comunicación, Quito, CIESPAL, 292.

14 Ibidem, 97. 
cación desde la comunicación. Diferentes perspectivas abordan el estudio de los actores, pero aquí no nos detendremos en ellas ${ }^{15}$.

Las evaluaciones del presente, que se vienen proponiendo desde la perspectiva de los autores citados, implican la realización de un diagnóstico, como parte integrante de la planificación. Y esto se corresponde con la idea de que la sociedad no puede ser abordada desde una primera lectura, ya que no es transparente; por lo que, siguiendo a Prieto, es necesaria la perspectiva histórica: «[...] un diagnóstico consiste en una lectura esencial de determinada situación social, desde una perspectiva histórica ${ }^{16}$. Uranga propone el diagnóstico como dinámico, y lo desarrolla desde la comunicación, entendiéndolo como «parte integral del proceso de análisis e investigación, es una tarea destinada a discernir los diferentes componentes comunicacionales de una determinada situación ${ }^{17}$. El diagnóstico será, en definitiva, el que ponga en evidencia las imágenes de futuro que se materializan en las prácticas discursivas (imaginarios, construcciones, enunciados, representaciones) de los actores sociales que intervienen en los procesos que se estudian.

Para Prieto, el diagnóstico también implica considerar el futuro, en tanto que «una percepción en profundidad del pasado y del presente se orienta hacia acciones futuras ${ }^{18}$ : futuro éste abierto, como se viene sosteniendo en este trabajo. A su vez, para Merello: «El diagnóstico es la resultante de una dialéctica entre el polo prospectivo - lo ideal-y la situación -lo real». ${ }^{19}$

Todos los conceptos desplegados en los párrafos precedentes son retomados a manera de síntesis, de forma crítica, e integradora, por el ya citado Washington Uranga, quien considera que «la gestión de procesos comunicacionales es un conjunto complejo de acciones y procedimientos que engloban el diagnóstico, la planificación, la ejecución y la evaluación» ${ }^{20}$ en un «todo integrado».

Gestionar la complejidad de estos procesos implica pensar en un desarrollo de diferentes acciones que se interrelacionan, se encadenan y se definen entre ellas. Todo ese gran conjunto de procesos se especifica en lo que Uranga define como «marco global de la gestión», que incluye las siguientes fases: diagnóstico desde la comunicación; planificación desde la comunicación; ejecución y evaluación.

Quedan así planteadas las relaciones entre los principales conceptos de la planificación desde la comunicación. El desarrollo operacional de esta perspectiva completa excedería los límites de este trabajo, por lo que avanzaremos sobre algunas consideraciones desde la semiótica, con objeto de poner de relieve la contribución que ésta puede aportar en el ámbito de la planificación.

15 En caso de interés se sugiere ver: MoJiCA, F. J. (2005): La construcción del futuro, Bogotá, CAB- Univ. Externado de Colombia, 148.

16 PRieto (1990), op. cit., 17.

17 Uranga, W., «Prospectiva... », 30.

18 PRieto (1990), op. cit., 291.

19 Merello (1973), op. cit., 24.

20 Uranga, W., «Prospectiva... », 2. 


\section{Semiótica y Planificación}

\subsection{La perspectiva}

La obra de Charles Sanders Peirce ha generado una vasta cantidad de lecturas, con algunas diferencias en su aplicación de acuerdo a la perspectiva involucrada. Esto no molestaría al autor, quien, como es conocido, ha incluido al interpretante en la estructura del signo, considerando explícitamente que éste a su vez puede devenir en signo, el que por lo tanto tendrá su propio interpretante, «y así sucesivamente ad infinitum» ${ }^{21}$.

Acá recuperamos el interpretante que la obra de Peirce generó en Juan Magariños de Morentín, y revisaremos su definición de signo y el planteo que realizó en relación a los nueve signos.

Pero antes, ¿por qué la perspectiva peirceana?. Porque consideramos que, además de ser una propuesta comunicacional, es un desarrollo de instancias de relación lógica que proponen un orden, una interrelación, un tiempo y hasta una estrategia, por lo que puede mantener una estrecha relación con la planificación (y éste es nuestro interpretante, generado en Peirce).

\subsection{El signo}

Magariños de Morentín toma la definición habitualmente aceptada de signo, propuesta por Peirce, para quien: «un signo o representamen, es algo que está para alguien, por algo, en algún aspecto o disposición» ${ }^{22}$. Es la totalidad del signo, ese algo la que se dirige a alguien, produciendo la creación en él de otro signo, que se constituye como el interpretante del primero. Por otro lado, siguiendo este planteamiento, todo signo (ese algo) «es el sustituto de algo, a lo que denomina su objeto» ${ }^{23}$. Del desarrollo de las relaciones lógicas planteadas entre estas entidades, resulta que un signo tendrá como objeto otro signo, llegando a un esquema triádico cuyos integrantes pueden ponerse en relación como se muestra en la Figura $1^{24}$.

PeIrCE, Ch. S. (1986): La ciencia de la semiótica, Buenos Aires, Ediciones Nueva Visión, 59.

22 Magariños de Morentín, J. A. (2008): La semiótica de los bordes, Córdoba, Comunicarte, 102.

Ibidem, 103.

24 Reproducido a partir de: Ibídem, 104. 
Fig. 1. Esquema del Signo Peirceano

\section{Representamen}

Es decir Algo (para alguien por algo y en alguna relación)

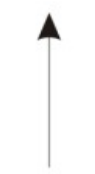

\section{Fundamento}

Que también es signo, o sea Algo (Para alguien, por algo y en alguna relación)

\section{Interpretante}

Que también es signo, o sea Algo (para alguien, por algo y en alguna relación)

Magariños traduce «Ground» como «fundamento» (respetando esta traducción a lo largo de su obra) en coincidencia con lo que plantean tanto Armando Sercovich $^{25}$, como Roberto Marafioti ${ }^{26}$.

En sentido similar a esta concepción de signo, Eco cita a Peirce recuperando la intensidad de la relación triádica:

«Una acción o influencia que es o implica una cooperación de tres sujetos, como por ejemplo, un signo, su objeto y su interpretante; no siendo tal influencia trirrelativa reductible a una influencia entre parejas» ${ }^{27}$. Definición que evoca la definición complementaria de signo como algo que está ante los ojos de alguien en lugar de otra cosa, en algún aspecto y carácter ${ }^{28}$.

Cada uno de estos componentes sígnicos, el representamen, el objeto o fundamento y el interpretante, implican para Peirce que pueden ser considerados como signos, por lo que el representamen también tendrá sus tres componentes sígnicos en tanto que es un signo, con su representamen, fundamento e interpretante; el fundamento tendrá su representamen, fundamento e interpretante; y por último el interpretante también es un signo, por lo que está constituido a su vez por esas tres partes: un representamen, un fundamento y un interpretante. De esta manera «se ha generado, en forma recurrente, los nueve signos que son la base primaria de toda clasificación semiótica» ${ }^{29}$. Así, al desplegar las relaciones de los tres signos principales, se pueden obtener los nueve signos que dan lugar a la semiótica general propuesta por Peirce.

25 PeIRCE, Ch. S., La ciencia..., 21 (Nota al pie del traductor).

26 Marafioti, R. (2004): Charles S. Peirce: el éxtasis de los signos, Buenos Aires, Biblos, 74 (Nota aclaratoria al pie).

27 Peirce, Ch. S. (1933-1948): Collected Papers, (C.P. 5.484), citado en ECO, U. (1990): Los límites de la interpretación, Barcelona, Lumen, 1992, 65.

28 Ibidem, 65.

29 Magariños de Morentín, (2008), op. cit., 108. 
La relación planteada entre estos signos no se corresponde con taxonomías cerradas, sino con relaciones lógicas que se van desarrollando en un orden también lógico: la primeridad, en cuanto la posibilidad de la forma de algo; la segundidad, que es la instancia que sigue en la que esas formas comienzan a concretarse en existentes; y la terceridad o instancia en la que esos existentes son valorados o normativizados.

\subsection{El planteo operativo de los nueve signos}

Magariños de Morentín le da a la relación entre los nueve signos y su correspondencia lógica, tal como Peirce los expone en su Gramática Especulativa, un tratamiento particular que merece ser examinada con cierto detenimiento y que se resume en el siguiente cuadro:

Fig. 2. Dinámica de los nueve signos desde la perspectiva de Magariños de Morentín

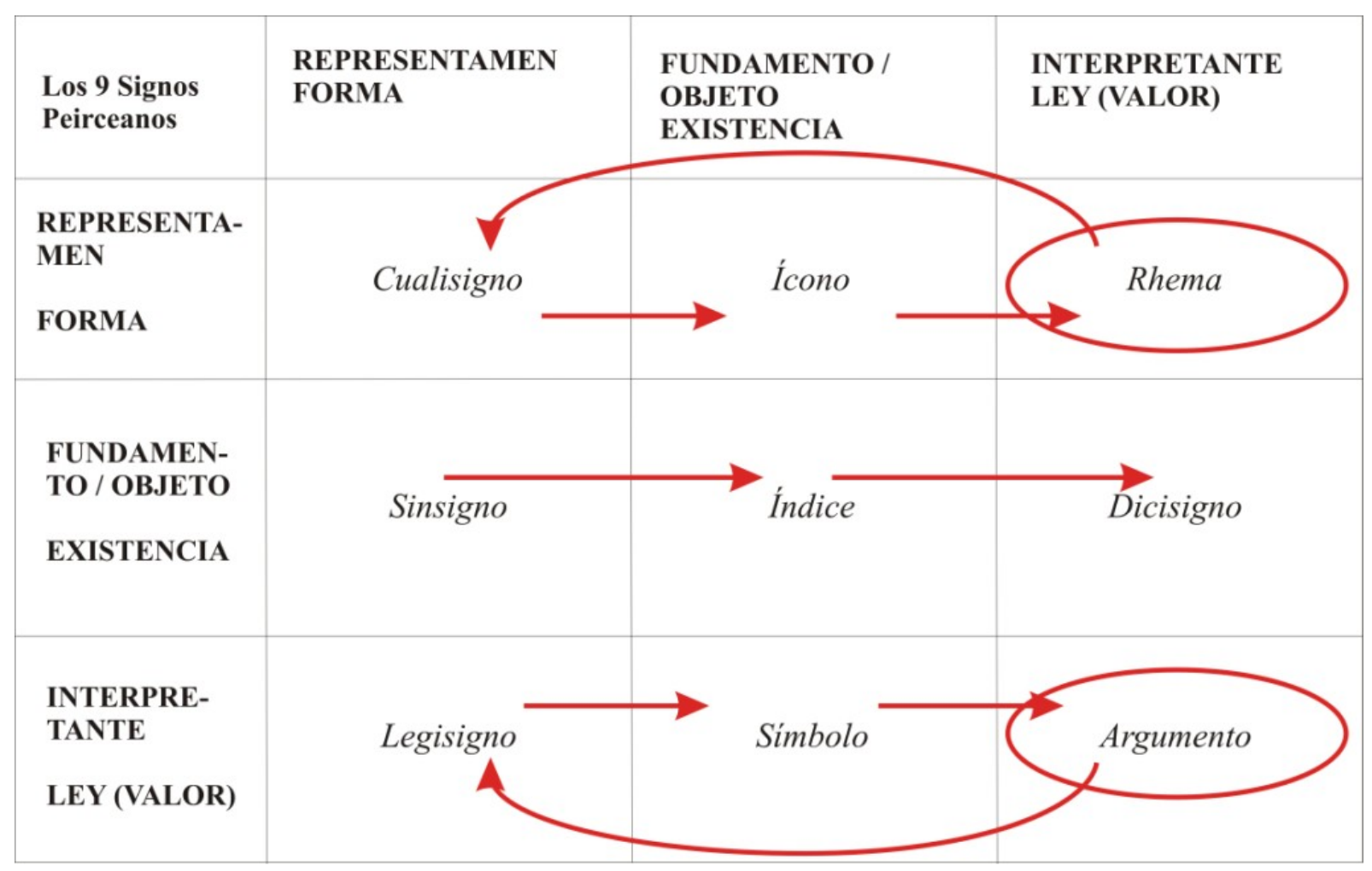

El primero de los nueve signos es el cualisigno, que Peirce concibe del siguiente modo: «A Qualisign is a quality which is a Sign. It cannot actually act as a sign until it is embodied; but the embodiment has nothing to do with its character as a sign ${ }^{30}$ (para cada uno de los nueve signos peirceanos tomaremos de aquí en adelante las traduccio-

30 Peirce, Ch. S. (1931): Collected Papers of Charles Sanders Peirce, Cambridge, The Belknap Press of Harvard University Press, 1965, 2.244. 
nes de Armando Sercovich ${ }^{31}$, quien, como referencia, traduce el texto anterior del siguiente modo: «Un Cualisigno es una cualidad que es un Signo. No puede actuar verdaderamente como un signo hasta tanto no esté formulado; pero la formulación no tiene relación alguna con su carácter en tanto signo»). La primera parte de esta definición es recuperada por Magariños ${ }^{32}$ para plantear que este signo:

[...] toma del objeto y transfiere a un interpretante el mero aspecto formal de tal objeto. Constituye la forma de la posibilidad («tone» o tono), extrayéndola operativamente del sistema constituido por el Rhema, por ser dicha forma uno de los tipos o elementos que lo constituyen, por lo que también será en el Rhema donde encuentre su valoración.

Magariños no continúa presentando al segundo signo del primer correlato, $\mathrm{y}$ rompe este orden propuesto por Peirce para, en cambio, definir al ícono:

Se trata de un signo que toma del objeto y transfiere al interpretante la posibilidad de que una determinada forma exista en tal objeto. Constituye la existencia de la posibilidad de la forma, la cual se obtiene integrando los cualisignos previamente seleccionados ${ }^{33}$.

Aquí también mantiene una estrecha relación con la definición propuesta por Peirce: «An Icon is a sign which refers to the Object that it denotes merely by virtue of characters of its own, and which it possesses, just the same, whether any such Object actually exists or not $»^{34}$. («Un Í Ícono es un signo que se refiere al Objeto al que denota meramente en virtud de caracteres que le son propios, y que posee igualmente exista o no exista tal Objeto» ${ }^{35}$ ).

La tercera posibilidad, dentro de la primeridad planteada por Magariños, o el valor de la forma, está dada por el Rhema, al que considera como un signo que:

Constituye el sistema de las formas posibles, vigentes en un momento dado de una comunidad, y del que el productor extrae las cualidades con las que producirá el ícono, y a cuyo conocimiento el intérprete acude (memoria asociativa) para comprender y valorar el icono propuesto por el productor ${ }^{36}$.

Peirce propone como Rhema al signo que «para su interpretante, es un Signo de Posibilidad cualitativa, vale decir, se entiende que representa tal o cual clase de Objeto posible» ${ }^{37}$ ( A Rheme is a Sign which, for its Interpretant, is a Sign of qua-

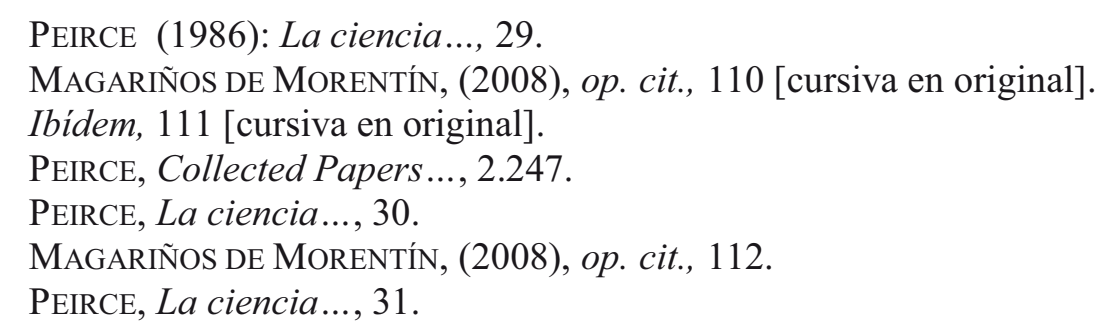


litative possibility, that is, is understood as representing such and such a kind of posible Object» ${ }^{38}$ ).

De esta manera Magariños plantea una fuerte relación entre Rhema (sistema del que se extraen los cualisignos), Cualisigno (elemento constitutivo del ícono, tomado del sistema), e Ícono (la existencia de la forma, constituida por los cualisignos).

En la instancia de la segundidad, o la existencia, Peirce plantea al Sinsigno (el segundo signo del primer correlato) como «[...] una cosa o evento real y verdaderamente existente que es un signo. Puede serlo únicamente a través de sus cualidades $[\ldots] \gg{ }^{39}(«[\ldots]$ an actual existent thing or event wich is a sign. It can only be so through its qualities $\left.[\ldots]{ }^{40}\right)$. Magariños lo entiende como

[...] un signo que toma del objeto y transfiere al interpretante las características formales que pueden existir en tal objeto. Constituye una concreta posibilidad para la existencia de un signo; aquella materia prima disponible («token» o ejemplar) en el contexto (o mundo) de su productor, que intervendrá (o ha intervenido) efectivamente en la producción del signo en estudio ${ }^{41}$.

Magariños toma el siguiente fragmento de los Collected Papers de Peirce, para referirse al Índice:

«Is a Sign which refers to the Object that it denotes by virtue of being really affected by that Object» ( «Es un Signo que se refiere al Objeto que denota en virtud de estar afectado realmente por ese Objeto»; parágrafo 2.248). Se trata de un signo que toma del objeto y transfiere al interpretante la concreta existencia material de tal objeto. Constituye la efectiva existencia actual de un signo, construido con el o los Sinsignos que correspondan. ${ }^{42}$

El tercer signo de la segundidad, o el valor de la existencia, está dado por el Dicisigno o Signo dicente. La particularidad que este signo adquiere en la lectura de Magariños es la de su valoración contextual:

Constituye la valoración que alcanza determinado signo al percibírselo materialmente integrado a determinado contexto, en función de cuyo entorno el productor evaluará la materialidad de las cualidades que le atribuirá al índice, y a cuyo conocimiento el intérprete acudirá (memoria asociativa) para comprender y valorar el índice propuesto por el productor ${ }^{43}$

\footnotetext{
38 PeIrCe, Collected Papers..., 2.250.

PeIRCE, La ciencia ..., 29.

PEIRCE, Collected Papers..., 2.245.

MAGARIÑos DE MORENTín, (2008), op. cit., 113 [cursiva en original].

Ibidem [cursiva en original].

Ibidem, 114-115.
} 
Magariños encuentra la posibilidad de fundamentar esto indicando que al principio del parágrafo 2.250 Peirce plantea «[...]a Dicisign or Dicent Sign (that is, a proposition or quasi-proposition)[...] $»^{44}$ («[...] un Dicisigno o Signo Dicente (esto es, una proposición o cuasi-proposición) $[\ldots] »{ }^{45}$ ). De manera que el valor de signo estaría dado en que contiene la aptitud de integrar una proposición, para llegar a formar parte de un contexto, donde el signo se actualizaría. El Dicisigno se refiere al valor (columna del interpretante) de la existencia (hilera del fundamento). Por lo tanto se trata de un signo «que toma del objeto y transfiere al interpretante la identificación de tal objeto en el contexto existencial al que pertenece» ${ }^{46}$.

Entonces, la relación entre estos tres signos de la segundidad estaría dada de la siguiente manera: los sinsignos servirían de materia prima para la conformación del índice, el que se pondrá en valoración en contexto (dicisigno). Indica Magariños que, de manera contraria a como ocurre con el Rhema, que cumple la función de puerta de entrada en un sistema, el Dicisigno señala la puerta de salida del sistema.

Para Peirce, el tercer signo de la primera división (o primer correlato) es el legisigno, el que «es una ley que es un Signo. Esta ley es generalmente establecida por los hombres. Todo signo convencional es un legisigno (pero no recíprocamente) ${ }^{47}$ («is a law that is a Sign. This law is usually established by men. Every conventional sign is a legising (but not conversely) ${ }^{48}$ ). Para Magariños ${ }^{49}$ :

Constituye la norma, regla o ley que confiere la posibilidad de valoración convencional que puede adquirir un signo, constituyéndose en Símbolo, extrayéndolas operativamente del sistema identificado como Argumento, por ser uno de los tipos o elementos normativos que lo constituyen, por lo que también será en el Argumento donde encuentre su valoración.

El Símbolo es concebido por Magariños de Morentín como la existencia de la ley, o, mejor dicho, «la existencia de la convención incorporada al signo, la cual se obtiene integrando los Legisignos previamente seleccionados ${ }^{50}$. Peirce define al símbolo como: «a Sign which refers to the Object that it denotes by virtue of a law, usually an association of general ideas, which operates to cause the Symbol to be interpreted as referring to that Object» ${ }^{51}$ («un signo que se refiere al Objeto que denota en virtud de una ley, usualmente una asociación de ideas generales que operan de modo tal que son la causa de que el Símbolo se interprete como referido a dicho Objeto» ${ }^{52}$ ).

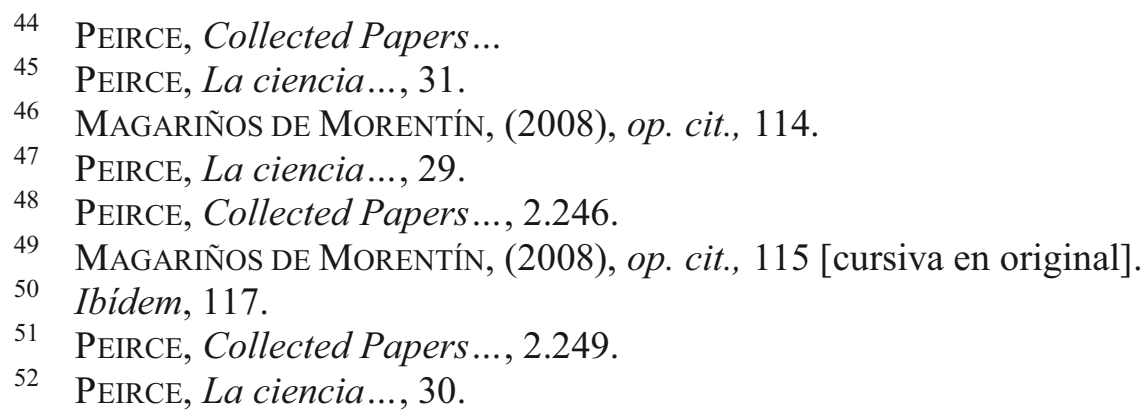


Finalmente, el Argumento, como el último de los nueve signos que surgen de estas relaciones triádicas, es definido por Peirce como «un Signo de ley. O también podemos decir que [...] un Argumento es un Signo que se entiende representa a su Objeto en su carácter de Signo» ${ }^{53}$ («[...] is a Sign of Law. Or we may say that $[. .$. an Argument is a Sign which is understood to represent its Object in its character as Sign ${ }^{54}$ ). Para Magariños de Morentín ${ }^{55}$, el Argumento:

Constituye el sistema de normas o valores convencionales efectivamente vigentes en una determinada comunidad, del cual el productor extrae las convenciones a las que identificará como el o los Legisignos con los que producirá el Símbolo, y a cuyo conocimiento el intérprete acudirá (memoria asociativa) para comprender y valorar el Símbolo propuesto por el productor.

Magariños sostiene que el Rhema es la «puerta de entrada de los signos en un sistema, ya que señalaba la posibilidad de que se pudiese atribuir a un signo un valor o una legalidad»; por su parte el Dicisigno es la «puerta de salida de los signos del sistema, ya que señalaba las condiciones bajo las cuales un signo podría adquirir (en cuanto existente) la legalidad pertinente a un determinado contexto»; mientras que el Argumento «es el signo que ordena un sistema hacia su propia interioridad $»^{56}$.

En esta última instancia, o en esta terceridad, la dinámica que relaciona los tres signos es similar a la que se planteó en un primer lugar: los Legisignos son seleccionados del sistema (Argumento) para configurar un Símbolo, el (o los) que tendrá(n) la posibilidad de modificar (transformar) ese sistema.

Hemos intentado mostrar aquí de qué manera Magariños de Morentín considera la relación de los nueve signos, haciendo referencia a su dinámica, no por los tres correlatos, sino a partir de una lectura horizontal, permitiendo un desarrollo analítico.

\subsection{Los nueve signos: aplicación a la planificación prospectiva}

Los principales disparadores, o posibilidades de relacionar la semiótica con la planificación desde la comunicación han sido una serie de temas que tienen como objetivo la interpretación, la comunicación misma, la representación o los aspectos simbólicos, como explicamos en la sección 2. Ahora desarrollaremos los nueve signos, desde la perspectiva de Magariños de Morentín, considerando como punto de partida las Imágenes de futuro.

53 Ibidem, 31.

54 PEIRCE, Collected Papers..., 2.252.

55 Magariños de Morentín, (2008), op. cit., 119.

56 Ibídem, 119-120. 


\subsubsection{Imágenes de futuro}

El futuro es una de las principales categorías para poder pensar en la planificación prospectiva, en tanto que

[...] elige como punto de partida la construcción de imágenes de futuro para regresar sobre el presente con una mirada más compleja y enriquecida que permite reconocer presencias y ausencias imposibles de ser captadas solamente con los elementos que da la retrospectiva y el análisis del presente ${ }^{57}$.

Las imágenes de futuro, «como procesos de producción simbólica de los actores que ponen de manifiesto sueños, deseos y utopías» ${ }^{58}$, están constituidas por relatos, diferentes discursos de diversos actores implicados en una instancia problemática que conlleva el diseño de una planificación desde la comunicación.

De este modo, las imágenes de futuro tienen una carga de significación muy importante, y se constituyen en signos, en tanto que son construcciones que se generan para ubicarse en representación de otra cosa: un discurso actual que está en representación de aquello a lo que se quiere llegar, ese futuro deseado (posible, probable, etc.) será considerado ahora como signo (es decir que será: «Anything which determines something else (its interpretant) to refer to an object to which itself refers (its object) in the same way $[\ldots]\rangle{ }^{59}[\ll$ Cualquier cosa que determine a otra cosa (su interpretante) a referirse a un objeto al cual ella también se refiere (su objeto) de la misma manera $\left.[\ldots]\rangle^{60}\right]$

Al pensar esta categoría como signo y abriéndola en sus tres instancias, podemos tener lo que se presenta en la figura 3 :

Fig. 3. Imágenes de futuro

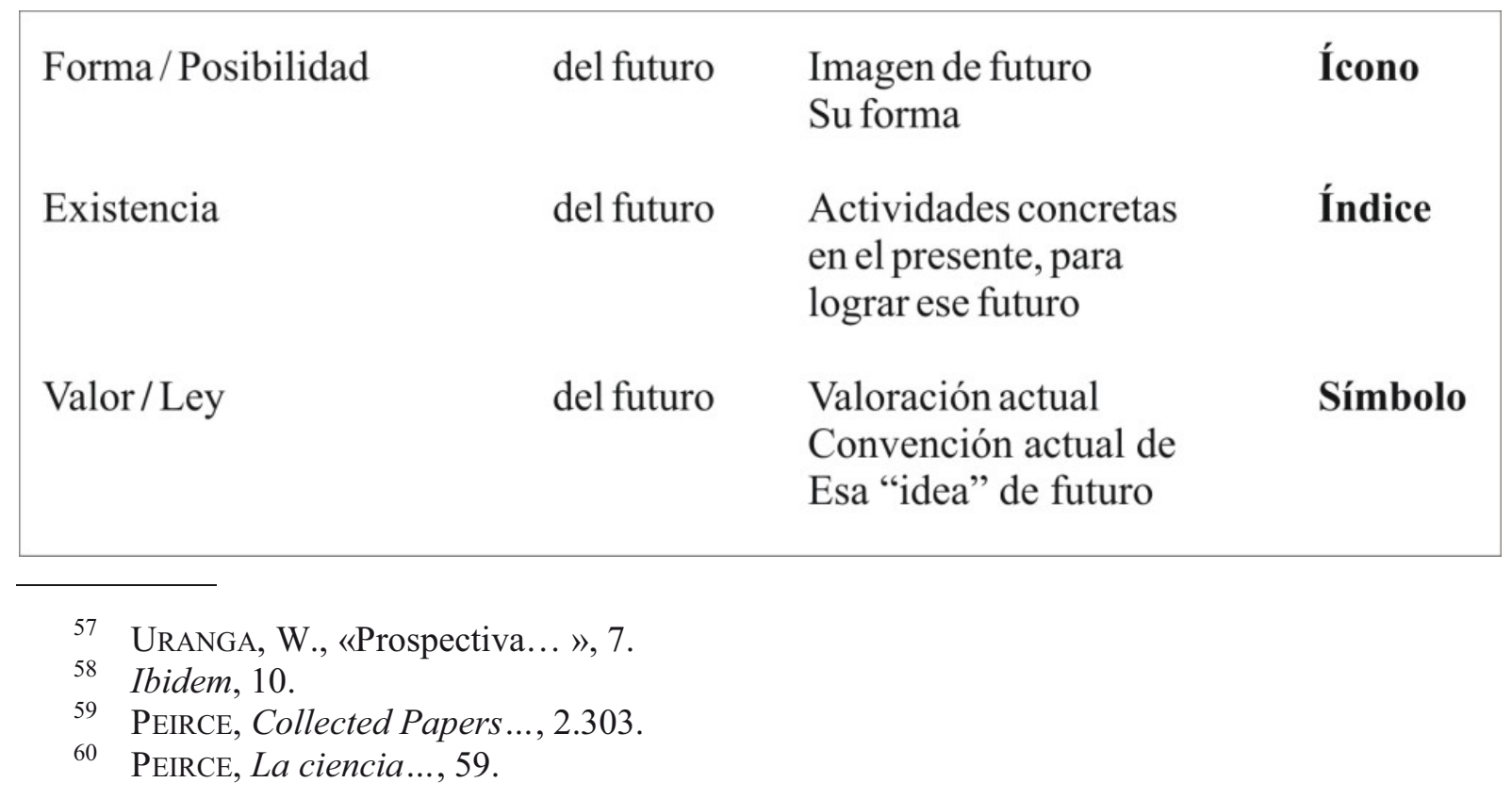


Al considerar su desarrollo en los nueve signos, logramos el cuadro representado en la figura 4 (nótese que en algunos de los signos hemos incorporado la referencia a los autores trabajados en la sección segunda para poder ubicar mejor las conceptualizaciones consideradas en esta figura):

Fig. 4. Desarrollo de los 9 Signos Peirceanos

\begin{tabular}{|c|c|c|c|}
\hline $\begin{array}{l}\text { Los } 9 \text { Signos } \\
\text { Peirceanos }\end{array}$ & $\begin{array}{l}\text { REPRESENTAMEN } \\
\text { FORMA }\end{array}$ & $\begin{array}{l}\text { FUNDAMENTO / } \\
\text { OBJETO } \\
\text { EXISTENCIA }\end{array}$ & $\begin{array}{l}\text { INTERPRETANTE } \\
\text { LEY (VALOR) }\end{array}$ \\
\hline $\begin{array}{l}\text { REPRESENTA- } \\
\text { MEN } \\
\text { FORMA }\end{array}$ & $\begin{array}{l}\text { Cualisigno } \\
\text { Diferentes posibilidades de } \\
\text { futuros, en cuanto formas } \\
\text { posibles: tendenciales, } \\
\text { referenciales, contrastados } \\
\text { (Maqueda Lafuente); } \\
\text { catastróficos, ideales, posibles } \\
\text { (Prieto). }\end{array}$ & $\begin{array}{l}\text { Ícono } \\
\text { Surgimiento de las principales } \\
\text { ideas en cuanto posibilidades } \\
\text { de futuro, plasmadas en } \\
\text { Imágenes de Futuro: } \\
\text { narraciones (guiones de } \\
\text { futurición - Uranga), en } \\
\text { bocetos, dibujos, croquis, } \\
\text { cuadros. Desarrollo de } \\
\text { escenarios posibles. } \\
\text { Consideración de brechas y } \\
\text { signos portadores de futuro. }\end{array}$ & $\begin{array}{l}\text { Rhema } \\
\text { Valoración en un sistema } \\
\text { social vigente, del que se } \\
\text { pueden extraer esas } \\
\text { posibilidades de futuro que } \\
\text { poseen ciertas cualidades } \\
\text { específicas perceptibles } \\
\text { (producción de discursos de } \\
\text { los diferentes actores). A su } \\
\text { vez conforma el sistema en el } \\
\text { que esas formas pueden ser } \\
\text { evaluadas (por parte de un } \\
\text { directorio, de profesionales, } \\
\text { de actores, de una sociedad) }\end{array}$ \\
\hline $\begin{array}{l}\text { FUNDAMEN- } \\
\text { TO / OBJETO } \\
\text { EXISTENCIA }\end{array}$ & $\begin{array}{l}\text { Sinsigno } \\
\text { Las diferentes acciones que } \\
\text { pueden desarrollarse en } \\
\text { relación a lo que se plantea en } \\
\text { los guiones de futurición. } \\
\text { Identificación de actores. } \\
\text { Las materias primas que se } \\
\text { utilizarán en la concreción de } \\
\text { las diferentes acciones: } \\
\text { soportes de comunicación, los } \\
\text { mensajes (su elección y } \\
\text { producción), los sistemas de } \\
\text { distribución (tangibles o } \\
\text { virtuales), tecnologías, la } \\
\text { organización de ese material, } \\
\text { actividades que permitan su } \\
\text { implementación (como } \\
\text { reuniones), etc. }\end{array}$ & $\begin{array}{l}\text { Índice } \\
\text { El resultado de actividades } \\
\text { concretas que permitan el } \\
\text { desarrollo de esas imágenes } \\
\text { de futuro, a partir de la } \\
\text { aplicación de los guiones de } \\
\text { futurición. } \\
\text { La imagen de futuro (en tanto } \\
\text { devenir) aún no es, pero } \\
\text { comienza a serlo en estas } \\
\text { acciones. Es decir que se } \\
\text { tratan de signos efectivamente } \\
\text { existentes. }\end{array}$ & $\begin{array}{l}\text { Dicisigno } \\
\text { Valoración en contexto de las } \\
\text { acciones entre ellas (para } \\
\text { considerar las posibilidades } \\
\text { de solapamiento de acciones y } \\
\text { de duplicación) y de éstas en } \\
\text { un contexto más amplio. } \\
\text { Considerar los cambios que } \\
\text { deben darse en el ámbito y en } \\
\text { el contexto (Uranga, Maqueda } \\
\text { Lafuente) }\end{array}$ \\
\hline $\begin{array}{l}\text { INTERPRE- } \\
\text { TANTE } \\
\text { LEY (VALOR) }\end{array}$ & $\begin{array}{l}\text { Legisigno } \\
\text { Posibles valoraciones de la } \\
\text { nueva estrategia de } \\
\text { comunicación (acciones } \\
\text { planificadas) por parte de los } \\
\text { diferentes actores. }\end{array}$ & $\begin{array}{l}\text { Símbolo } \\
\text { Significados } \\
\text { (interpretaciones) } \\
\text { efectivamente producidos de } \\
\text { las acciones planificadas. }\end{array}$ & $\begin{array}{l}\text { Argumento } \\
\text { Sistema de representaciones y } \\
\text { valores compartidos por todos } \\
\text { los participantes y por los } \\
\text { sujetos integrantes de la } \\
\text { comunidad en la que se } \\
\text { implementa, en un } \\
\text { determinado momento } \\
\text { histórico. } \\
\text { El sistema } \\
\text { interpretativo/valorativo } \\
\text { puede verse afectado. } \\
\text { Conceptos y } \\
\text { posicionamientos políticos e } \\
\text { ideológicos (Uranga) }\end{array}$ \\
\hline
\end{tabular}


Las imágenes de futuro tienen, de este modo, la siguiente plasmación semiótica:

1. Cualisigno: se trata de los componentes seleccionados del sistema (Rhema) que permitirán la conformación del Ícono. Se considera el aspecto formal, en cuanto formas posibles de lo que luego serán los escenarios que integren la imagen de futurición.

2. Ícono: son las imágenes de futuro propiamente dichas, en tanto que se proponen como devenir del futuro posible, hasta que este llegue. Por esta razón aún son una posibilidad. Implican la elaboración de los guiones de futurición considerando la posibilidad de que sean plasmados en narraciones (siguiendo a Uranga) pero también la posibilidad de incluir bocetos, dibujos, croquis, cuadros, es decir, otras semiosis (otras naturalezas discursivas). Consideramos que pensar en otras formas de manifestar un futuro deseado, no sólo a través de la palabra, implica un proceso de manifestación (y también un proceso productivo) diferente, involucrando también otras formas cognitivas y expresivas. El ícono implica el desarrollo de los escenarios posibles, pero ahora sí con su forma definida (tendenciales, catastróficos, contrastados o los que se hayan considerado como los más adecuados). Será en este momento en el que deban considerarse, además, las brechas y los signos portadores de futuro.

3. Rhema: será la valoración de las cualidades (o formas) que constituyen las imágenes de futuro, por parte de la comunidad que las ha creado. También es el sistema (y en tanto sistema siempre será virtual desde la semiótica) del que se han extraído esas cualidades, como cualisignos para la conformación del ícono. Por lo tanto, podrán transformar el rhema, con la posibilidad de cambio que puede darse a partir de las combinaciones novedosas de esos cualisignos en el ícono, impactando finalmente en el sistema del que fueron tomados (con la posible generación de nuevas formas de imágenes de futuro).

4. Sinsigno: serán los aspectos que, como materia prima, conformarán el índice o el existente concreto. Por lo tanto, serán las acciones planteadas en los guiones de futurición, la identificación de actores concretos (quiénes intervendrán en qué acciones determinadas) y un estudio, detalle y uso concreto de los materiales (existentes, en tanto recursos físicos, económicos, materiales, etc.) necesarios para ello.

5. Índice: es la existencia concreta de lo que el conjunto de sinsignos logra materializar. Entonces serán los resultados que de las acciones concretas desarrolladas se obtengan (después de la transformación de los sinsignos), que permitirán concretar lo planteado como imagen de futuro, a fin de acercarse a ella. Se trata del encadenamiento de determinadas acciones y generación de existentes.

6. Dicisigno: será la valoración en contexto del resultado (materializado) de las acciones previstas. Es decir, que se valora la relación de los diferentes existentes resultantes de determinadas acciones previstas en la planificación. Es- 
ta valoración permite evaluar y controlar la superposición de acciones y, además, considerar el factor de cambio que, siguiendo a Uranga ${ }^{61}$, debe darse en las instancias de contexto.

7. Legisigno: es el signo que está conformado por las posibles valoraciones que pueden devenir, de acuerdo a la legalidad (convención) que de las imágenes de futuro diseñadas pueda existir. Como se trata de la forma o posibilidad del Valor, aún no serán las interpretaciones definitivas (que se darán como símbolo), sino que son las posibles. Éstas se originan en el sistema (que siempre será virtual). Deberán ser consideradas en los procesos de planificación.

8. Símbolo: es la valoración concreta o la interpretación actual, efectivamente producidas, que adquiere un fenómeno (en este caso la estrategia generada desde la planificación en relación al establecimiento de ese futuro) en un determinado momento de una determinada sociedad. Será, entonces, la interpretación que deviene de todo el sistema planificado.

9. Argumento: es el sistema de representaciones, en un determinado momento histórico, de la sociedad para la que se ha planificado y en la que se ha planificado. El sistema interpretativo/valorativo puede verse afectado por los significados proferidos por la implementación de las estrategias previstas en la planificación. Es decir, que lo que se sugiere aquí es considerar la posibilidad de impacto interpretativo que puede tener una planificación prospectiva en una sociedad (en la comunidad en la que, y para la que, se desarrolla). En este sentido resulta pertinente considerar cambios o impactos en los conceptos y los posicionamientos políticos e ideológicos de los que Uranga ${ }^{62}$ habla, como factores identificados previamente en los guiones de futurición.

Esta perspectiva, vista desde la semiótica, permite abrir el panorama de la planificación prospectiva desde la comunicación en otros sentidos posibles, planteando otras relaciones entre las categorías previstas por la prospectiva.

La posibilidad de pensar en la valoración que adquiere cada instancia en la terceridad (el tercer correlato peirceano): el valor de la forma (rhema), el valor de la existencia (dicisigno) y el valor de la ley (argumento), como desarrollos a partir del interpretante, permite incorporar en cada instancia la perspectiva del intérprete, del destinatario, por lo que implica la constante evaluación de su factibilidad y aceptabilidad, como también plantean Merello y Uranga (la necesidad de una planificación participativa). En este sentido también puede sostenerse que continúa siendo una propuesta desde la comunicación.

61 URANGA, W., «Prospectiva... », 34.
62 Ibidem, 34. 


\subsubsection{Posibilidades de aplicación en programas especificos}

Es posible considerar esta perspectiva semiótica para la planificación de actividades más acotadas y específicas, tales como planes, programas o proyectos. En el cuadro desarrollado en la figura 5 hemos abordado la planificación de un Plan de Comunicación y de un Proyecto de una Revista interna (extrapolable a cualquier soporte particular), para una empresa X. A fin de mostrar las relaciones, se incorporan los detalles de ambas planificaciones en un mismo cuadro: los párrafos en redonda se corresponden con el Plan de Comunicación y los párrafos en cursivas con el desarrollo de la revista.

Fig. 5. Desarrollo de los 9 Signos Peirceanos para un Plan y un Proyecto

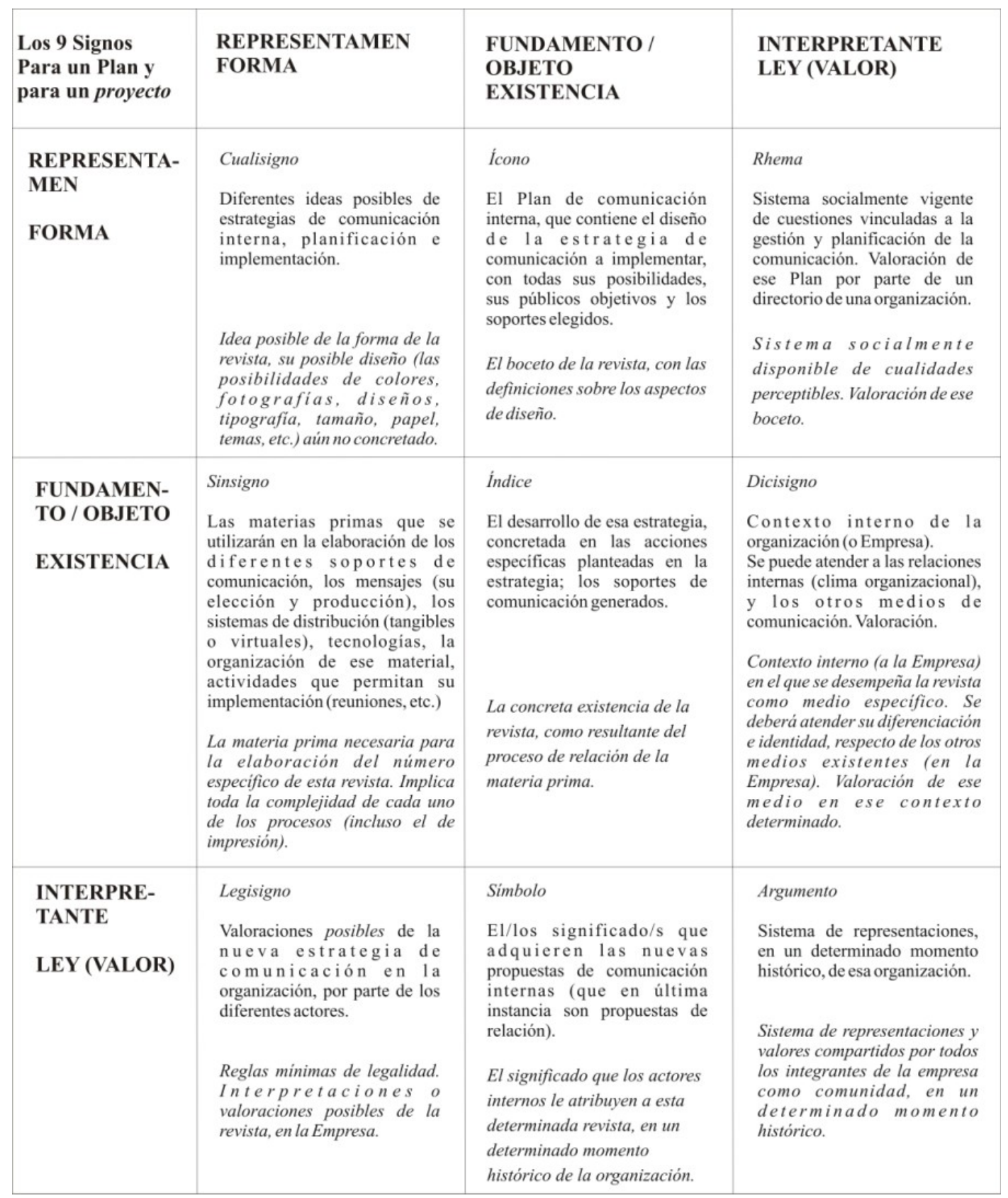




\section{Reflexiones finales}

En este trabajo exploramos algunas relaciones entre la semiótica y la planificación prospectiva desde la comunicación, dejando descripto un marco de acción posible a partir del desarrollo de los nueve signos de Peirce para tres ámbitos: uno general y amplio, el de la planificación prospectiva desde la comunicación, y dos más acotados y concretos (un plan de comunicación y una revista interna). En relación al primero, intentamos desarrollar un marco teórico con consideraciones metodológicas generales para la planificación prospectiva, incorporando en los nueve signos los principales conceptos.

Como ejemplos desarrollados desde lo hipotético, merecen seguir siendo profundizados y ser tomados como aspectos exploratorios.

Por todo lo visto hasta el momento, consideramos que la semiótica no entra en competencia con las propuestas de planificación abordadas, sino que permite pensarlas a partir de otras relaciones.

Un punto interesante para reflexionar y profundizar, que puede ser valorado como una apertura, es el de considerar las posibilidades de estudios diacrónicos, procesuales, desde la semiótica. Para Francisco Mojica, la planificación normativa y tradicional «operaba a nivel sincrónico pero omitía ver la realidad en la dimensión diacrónica» ${ }^{63}$, y por ello propone la incorporación de lo diacrónico en la planificación prospectiva.

Los estudios diacrónicos permiten prestar atención a las modificaciones que se generan en las significaciones -valoraciones- interpretaciones que se dan en una sociedad determinada en un momento determinado (trátese de contextos acotados como los de una organización o de grupos sociales más grandes) con respecto a otras que pueden darse en otro momento determinado en relación a ese mismo grupo de sujetos. Lo que se plantea es desarrollar un estudio, por ejemplo a partir de los nueve signos, en momentos diferentes, para permitir identificar las modificaciones y cambios generados en niveles interpretativos. Para ello es preciso acudir a las semióticas particulares y poder reforzar las actividades con entrevistas (para operar desde lo simbólico), el estudio de los comportamientos y de los objetos (en cuanto aquello que implique lo indicial), y cómo se actúa y se interpreta en relación a la producción de las imágenes materiales visuales (aspecto icónico) que pudieran estar implicadas.

63 Mojica (2005), op. cit., 148. 


\section{Referencias bibliográficas}

ECO, U. (1990): Los límites de la interpretación, Barcelona, Lumen, 1992.

Magariños de Morentín, J. A. (2008): La semiótica de los bordes, Córdoba (Argentina), Comunicarte.

MAQUEDA LAFUENTE, J. (1996): «Conexión entre la prospectiva y la estrategia», en MAQUEDA LAFUENTE, J. (coord.), Cuadernos de dirección estratégica y planificación, Madrid, Díaz de Santos.

Marafioti, R. (2004): Charles S. Peirce: el éxtasis de los signos, Buenos Aires, Biblos.

Merello, A. (1973): Prospectiva. Teoría y práctica, Buenos Aires, Editorial Guadalupe.

MoJiCA, F. J. (2005): La construcción del futuro, Bogotá, CAB- Univ. Externado de Colombia.

PeIRCE, Ch. S. (1931-1965): Collected Papers of Charles Sanders Peirce, Cambridge, The Belknap Press of Harvard University Press.

PeIRCE, Ch. S. (1986): La ciencia de la semiótica, Buenos Aires, Ediciones Nueva Visión.

PRIETO, D. (1990): Diagnóstico de comunicación, Quito, CIESPAL.

URANGA, W. (2007): «Mirar desde la comunicación»,

http://www.catedras.fsoc.uba.ar/uranga/uranga_mirar_desde_la_comunicacion.pd Web visitada el 15/10/2010.

URANGA, W. (2008): «Prospectiva estratégica desde la comunicación», http://catedrarollie.com.ar/taller5/wp-content/uploads/2008/06/prospectiva-estrategicauranga.pdf. Web visitada el 28/04/2010. O resumen en www.catedras.fsoc.uba.ar/uranga/cuadro_proceso.doc. Web visitada el 15/10/2010.

Recibido: 29 de abril de 2010

Aceptado: 28 de enero de 2011 